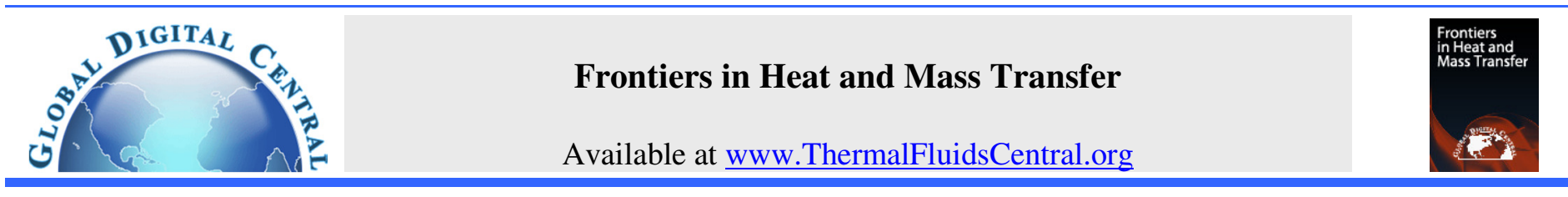

\title{
EFFECT OF CATTANEO-CHRISTOV HEAT FLUX ON NONLINEAR RADIATIVE MHD FLOW OF CASSON FLUID INDUCED BY A SEMI- INFINTE STRETCHING SURFACE
}

\author{
M. Sathish Kumar ${ }^{\mathrm{a}}$, N. Sandeep ${ }^{\mathrm{a},{ }^{*}}$, B. Rushi Kumar ${ }^{\mathrm{a}}$, J. Prakash ${ }^{\mathrm{b}}$ \\ ${ }^{a}$ Department of Mathematics, VIT University, Vellore, 632014, India \\ ${ }^{b}$ Department of Mathematics, University of Botswana, Private Bag 0022, Gaborone, Botswana.
}

\begin{abstract}
In this study, a numerical investigation is performed to analyse the flow and heat transfer characteristic of magnetohydrodynamic Casson fluid flow past a semi-infinite stretching surface in the presence of Cattaneo - Christov heat flux and nonlinear thermal radiation. Appropriate transformations are employed to reduce the governing partial differential equations into ordinary differential equations. Further, solutions of the ordinary differential equation are obtained with the aid of Runge- Kutta based shooting technique. The effect of various non- dimensional governing parameters on velocity and temperature fields for suction and injection cases are discussed with the help of graphs. Also computed and discussed the skin friction coefficient and local Nusselt number. It is found that momentum and thermal boundary layers are non-uniform for suction and injection cases. It is also found that heat transfer performance of Casson fluid is high in injection case when compared with the suction case.
\end{abstract}

Keywords: $M H D$, Cattaneo-Chritov heat flux, nonlinear radiation, Casson fluid and suction/injection.

\section{INTRODUCTION}

Investigations on Cattaneo-Christov heat flux over a stretching surface perceive many applications for engineering processes. This applications include drawing of plastic films, polymer extrusion, wires, fibre, glass and paper production, crystal growing, production of food, etc. present days great deal of work has been carried out to disclose the effect of Cattaneo-Christov heat flux on MHD flow past a stretching surface. The study of boundary layer flows over a stretching sheet was initially analysed by McCormack and Crane (1973). Gupta and Gupta (1977) explained the hydrodynamic fluid flow on heat and mass transfer over an isothermal stretching sheet with the effect of suction/blowing. The injection and suction effect on heat transfer over a stretching surface was examined by Elbashbeshy (1998). Vajravelu (2001) explained the heat transfer behaviour of a viscous fluid over a stretching sheet. Further, the researchers [Jafer et al. (2012, Rashidi et al. (2014), Abbasbandy et al. (2014))] analysed the heat and mass transfer characteristic of MHD flows over a stretching sheet by considering the various physical effects.

Heat transfer is involved in extensive ranging in engineering and industrial processes, like space cooling, energy production, biomedical application, etc. Heat conduction law is explained by Fouries (1822). Cattaneo (1948) examined the inclusion of relaxation for the Fourier's law with heat flux. The invariant formulation of the Cattaneo's model was explained by Christov (2009). Straugghan (2010) proposed the the Cattaneo-Christov model for the thermal convection in a Newtonian fluid. Further, the modification of Cattaneo- Christov equation is presented by Ciarletta and Straughan (2010). The MHD boundary layer flow over a flat sheet in the presence of non-uniform heat source and thermal radiation was studied by Subhas Abel and Mahesha (2008) and concluded that increasing the Prandtl number decreases the thermal boundary layer thickness. The influence of magnetic field and radiation on an unsteady mixed convection flow over a stretching surface with the effect of viscous dissipation and variable viscosity was examined by Sandeep et al. (2015). A steady MHD flow close to the stagnation point over stretching sheet was presented by Ramesh et al. (2012). The effect of thermal radiation on heat transfer nono fluid flow over a stretching sheet was proposed by Rashidi et al. (2014) and found that rising the value of nanoparticle volume fraction depreciate the velocity profile.

The study of Cattaneo- Chritov heat flux over an upper convected Maxwell fluid due to an exponentially stretching surface with thermal relaxation time on the boundary layer was analysed by Khan et al. (2015). Sathish kumar et al. (2016) studied the MHD stagnation point flow on heat and mass transfer over a nonlinear stretching sheet and concluded that increasing the magnetic field parameter reduces the heat transfer rate. The influence of electrically conducting fluid on MHD flow and heat transfer over a stretching surface in the presence of variable fluid properties was investigated by Vajravelu et al (2016). Hayat et al. (2016) studied the impact of Cattaneo-Christov heat flux on Maxwell fluid of variable thermal conductivity. Raju et al. (2016) discussed the three dimensional MHD flow over a nonlinearly stretching sheet with the effect of temperature dependent heat generation/absorption. The researcher [Han et al. (2014), Tibullo and Zampoli (2011), Hayet et al. (2016), Mustafa (2015), Hayat et al. (2016)] considered the CattaneoCheistov heat flux model and analysed the heat and mass transfer of Newtonian and non-Newtonian flows. Sulochana et al. (2016) discussed

*Corresponding author. Email: dr.nsrh@gmail.com 
the three- dimensional MHD flow, heat and mass transfer past a stretching sheet in the presence of Brownian motion and thermophoresis.

Recently Sandeep and Sulochana (2016) has studied the thermophoretic radiative MHD nanofluid on heat and mass transfer past an extending permeable sheet with suction/injection by taking into account with effect of viscous dissipation. The effect of magnetic field and nonlinear thermal radiation on viscoelastic fluid induced a stagnation point was presented by Animasaun et al. (2016). Sandeep et al. (2016) investigated the 3D Casson fluid on heat and mass transfer past a stagnation point with cross diffusion. Raju and Sandeep (2016) has studied the 3D unsteady MHD Casson-Carreau fluids induced a extending sheet with nonlinear thermal radiation. Sandeep (2016), Ramana Reddy et al. (2017) and Ali et al. (2017) studied the heat transfer behaviour of MHD flows.

In this study, we discussed the effect Caataneo-Christov heat flux on nonlinear radiative MHD flow of Casson fluid over a semi-infinite stretching surface in the presence of nonlinear thermal radiation. Appropriate transformations are employed to reduce the governing partial differential equations into ordinary differential equations. Further, solutions of the ordinary differential equation are obtained with the aid of Runge- Kutta based shooting technique. The effect of various nondimensional governing parameters on velocity and temperature fields for suction and injection cases are discussed with the help of graphs. Also computed and discussed the skin friction coefficient and local Nusselt number.

\section{FORMULATION OF THE PROBLEM}

Consider a steady, two-dimensional, incompressible, electrically conducting magnetohydrodynamic Casson fluid flow over a semiinfinite stretching surface. We consider a Cattneo-Christov heat flux model in the presence of nonlinear thermal radiation. Here $x$-axis is taken along the sheet and $y$ - axis is normal to it. $T_{w}$ and $T_{\infty}$ are the temperatures near and far away from the wall. A uniform magnetic field of strength $B_{0}$ is applied along the flow direction as depicted in Fig. 1. Induced magnetic field is neglected in this study.

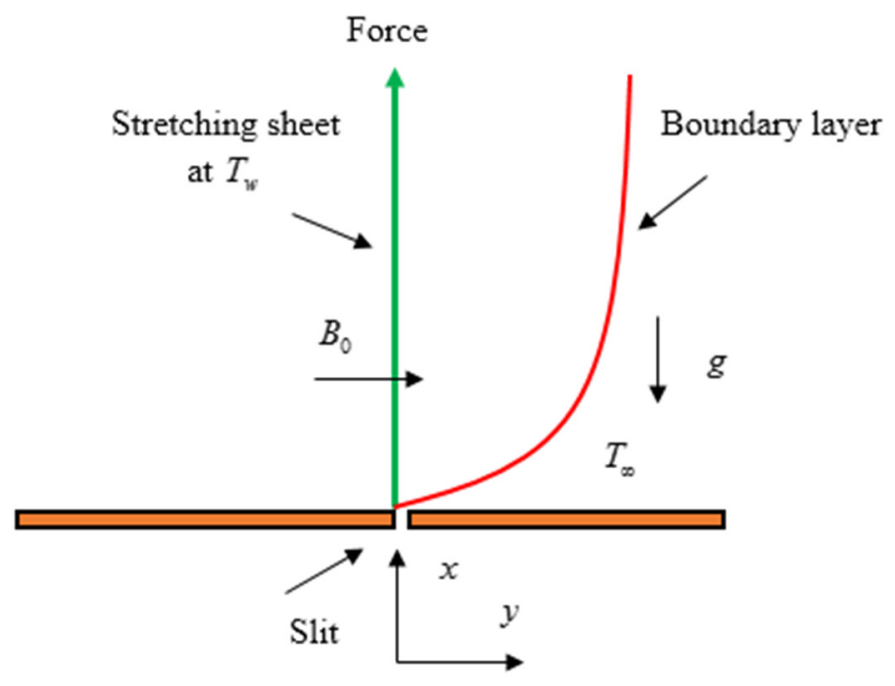

Under the above assumptions, the governing equations are

$\frac{\partial u}{\partial x}+\frac{\partial v}{\partial y}=0$

$u \frac{\partial u}{\partial x}+v \frac{\partial u}{\partial y}=\frac{1}{\rho}\left(\mu\left(1+\frac{1}{\delta}\right) \frac{\partial^{2} u}{\partial y^{2}}+g(\rho \beta)\left(T-T_{\infty}\right)-\sigma B_{0}^{2} u\right)$

$$
\begin{gathered}
u \frac{\partial T}{\partial x}+v \frac{\partial T}{\partial y}+\varepsilon\left(\begin{array}{c}
u \frac{\partial u}{\partial x} \frac{\partial T}{\partial x}+v \frac{\partial v}{\partial y} \frac{\partial T}{\partial T}+u \frac{\partial v}{\partial x} \frac{\partial T}{\partial y}+v \frac{\partial u}{\partial y} \frac{\partial T}{\partial x} \\
+2 u v \frac{\partial^{2} T}{\partial x \partial y}+u^{2} \frac{\partial^{2} T}{\partial x^{2}}+v^{2} \frac{\partial^{2} T}{\partial y^{2}}
\end{array}\right) \\
=\frac{k}{\rho c_{p}} \frac{\partial^{2} T}{\partial y^{2}}+\frac{16 \sigma^{*}}{3 k^{*}\left(\rho c_{p}\right)} \frac{\partial}{\partial y}\left(T^{3} \frac{\partial T}{\partial y}\right)
\end{gathered}
$$

The boundary conditions of Eqs. (1)- (3) are as follows:

$$
\begin{aligned}
& y=0 \Rightarrow u=u_{w}(x)=a x, v=v_{w}, T=T_{w,} \\
& y=\infty \Rightarrow u \rightarrow 0, T \rightarrow T_{\infty},
\end{aligned}
$$

The non-dimensional parameters are introduced as follows:

$$
\begin{aligned}
& \xi=\sqrt{\left(a / v_{f}\right)} y, u=\operatorname{axf} f^{\prime}(\xi), v=\sqrt{a v_{f}} f(\xi), \\
& \theta=\frac{T-T_{\infty}}{T_{w}-T_{\infty}},
\end{aligned}
$$

The reduced governing equations in non-dimensional form is

$$
\left(1+\frac{1}{\delta}\right) \frac{\partial^{3} f}{\partial \xi^{3}}+A\left(f \frac{\partial^{2} f}{\partial \xi^{2}}-\left(\frac{\partial f}{\partial \xi}\right)^{2}\right)-M \frac{\partial f}{\partial \xi}+\lambda \theta=0
$$

$$
\begin{gathered}
\frac{\partial^{2} \theta}{\partial \xi^{2}}+\operatorname{Pr} f \frac{\partial \theta}{\partial \xi}-\operatorname{Pr} \gamma f^{2} \frac{\partial^{2} \theta}{\partial \xi^{2}} \\
+R\left[\left(1+\left(\theta_{w}-1\right) \theta\right)^{3} \frac{\partial^{2} \theta}{\partial \xi^{2}}+3\left(\theta_{w}-1\right)\left(\frac{\partial \theta}{\partial \xi}\right)^{2}\left(1+\left(\theta_{w}-1\right) \theta\right)^{2}\right] \\
-\operatorname{Pr} \gamma f \frac{\partial f}{\partial \xi} \frac{\partial \theta}{\partial \xi}=0
\end{gathered}
$$

The corresponding boundary conditions become

$$
\begin{aligned}
& \eta=0 \Rightarrow f=S, f^{\prime}=1, \theta=1, \\
& \eta \rightarrow \infty \Rightarrow f^{\prime} \rightarrow 0, \theta=0,
\end{aligned}
$$

where $A$ is the viscosity ratio parameter, $\lambda$ is the buoyancy parameter, $M$ is the magnetic parameter, Pr is the Prandtl number and $R$ is the thermal radiation parameter, $\gamma$ is the thermal relaxation parameter, $\theta_{w}$ is the temperature ratio parameter, $S$ is the suction/injection parameter which are defined as follows:

Fig.1 Flow geometry of the problem 


$$
\begin{aligned}
& A=\frac{\mu_{f}}{\mu}, \lambda=\frac{g \beta_{f}\left(T_{w}-T_{\infty}\right)}{a u_{w}}, M=\frac{\sigma B_{0}^{2}}{a \rho_{f}}, \operatorname{Pr}=\frac{v_{f}}{\alpha \rho_{f}}, \\
& R=\frac{16 \sigma^{*} T_{\infty}^{3}}{3 k k^{*}}, \gamma=\varepsilon a, \theta=\frac{T_{w}}{T_{\infty}}, S=\frac{-v_{w}}{\sqrt{a v_{f}}},
\end{aligned}
$$

For engineering interest, the skin friction coefficient and the reduced Nusselt number are defined as follows:

$$
\begin{aligned}
& C_{f}=-\frac{\mu}{\rho_{f} u_{w}^{2}}\left(\frac{\partial u}{\partial y}\right)_{y=0}=-\frac{1}{A} \operatorname{Re}_{x}^{-1 / 2} f^{\prime \prime}(0) \\
& \Rightarrow C_{f}^{*}=C_{f} \operatorname{Re}_{x}^{1 / 2}=-\frac{1}{A} f^{\prime \prime}(0), \\
& N u=\left(\frac{x}{k_{f}\left(T_{w}-T_{\infty}\right)}\right)\left(k+\frac{16 \sigma^{*} T_{\infty}^{3}}{3 k}\right)\left(T_{y}\right)_{y=0} \\
& =-\operatorname{Re}_{x}^{1 / 2}\left(\frac{3 R+4}{3 R}\right) \theta^{\prime}(0), \\
& \Rightarrow N u^{*}=\frac{N u}{\operatorname{Re}_{x}^{1 / 2}}=-\left(\frac{3 R+4}{3 R}\right) \theta^{\prime}(0),
\end{aligned}
$$

\section{RESULT AND DISCUSSION}

The set of ordinary differential equations (6) and (7) subjected to the boundary conditions (8) are solved numerically using R-K based shooting technique. For numerical computations we considered the nondimensional parameter values as $A=\delta=0.5$, $\mathrm{R}=\mathrm{M}=\operatorname{Pr}=5, \theta_{w}=1.1, \lambda=\gamma=0.1, S= \pm 2$. Throughout our analysis we kept these values are common except the varied values are displayed in the respective graphs. The effect of viscosity ratio parameter $A$, magnetic field parameter $M$, radiation parameter $R$, buoyancy parameter $\lambda$, temperature ratio parameter $\theta_{w}$, thermal relaxation parameter $\gamma$ on velocity and temperature fields are discussed graphically.

Figs. 2 and 3 depict the Effect of magnetic field parameter on the velocity and temperature profiles for both suction and injection cases. We observed that increasing values of $M$ increases the temperature profile and depreciate the velocity profile for both suction and injection cases. Generally, the transverse magnetic field produce the body force, to be exact the Lorentz force, which opposes the motion of the fluid and encourage the thermal boundary layer thickness.

Figs. 4 and 5 depict the effect of thermal radiation parameter on velocity and temperature profiles for suction and injection cases. We observed that increasing values of radiation parameter increases the velocity and temperature profiles for suction and injection cases. Physically, rising values of radiation releases the additional heat to the flow. These causes to enhance the temperature field. The effect of Casson parameter on velocity and temperature of the fluid is demonstrated in Figs. 6 and 7. These graphs reveal that increasing values of Casson parameter enhances the temperature field and depreciate the velocity field. These may happen due to reduced viscosity nature for increasing values of $\delta$. Figs. 8 and 9 depict the velocity and temperature profiles for different values of $A$. It can be seen that the temperature profiles of the fluid increases and velocity profile decreases for rising values of $A$. In general, momentum boundary layer moves at various velocities and the velocity arises due to the shear stress between the layers that finally oppose the applied force.

The effect of buoyancy parameter on the velocity and temperature fields is plotted in Figs. 10 and 11. In can been seen that increasing values of $\lambda$ enhances the velocity profile and depreciate the temperature profile. Generally, rising values of buoyancy parameter develops the buoyancy forces along the flow direction. This leads to enhance the velocity field. The variations of temperature profiles for different values of temperature ratio parameter are depicted in Fig. 12. It is observed that increasing in the temperature ratio parameter leads to increase the fluid temperature in both cases. The effect of thermal relaxation parameter on the temperature profiles are shown in Fig. 13. The temperature profiles increase with increasing values of $\gamma$. Generally, for the higher values of thermal relaxation parameter we observed a nonconducting action which is answerable for increasing/decreasing behaviour of temperature profiles.

Table 1 depict the validation of the present results by comparing with the published results under some special and limited case. We found a favourable agreement of the present results with the published results. Tables 2 and 3 shows the influence of non-dimensional governing parameters $M, R, \delta, A, \lambda, \theta_{w}$, and $\gamma$ on skin friction coefficient and local

Nusselt number for suction/injection cases. It is evident that rising values of magnetic field parameter, Casson parameter, viscosity ratio parameter declines the heat transfer rate and friction factor for both suction and injection cases. But buoyancy parameter shows opposite results to above. Increasing values of thermal radiation parameter, temperature ratio parameter and thermal relaxation parameter enhances the skin friction coefficient and depreciates the local Nusselt number for both cases.

Table 1 Comparison of the values of $-\theta^{\prime}(0)$ with published data when $\operatorname{Pr}=2, \gamma=0$.

\begin{tabular}{|c|c|c|c|}
\hline$S$ & $R$ & Rashidi et al.[28] & Present Results \\
\hline-0.5 & $4 / 3$ & 0.2877 & 0.2877 \\
\hline-0.5 & 0 & 0.3990 & 0.3990 \\
\hline 0 & $4 / 3$ & 0.4434 & 0.4434 \\
\hline 0 & 0 & 0.7643 & 0.7643 \\
\hline 0.5 & $4 / 3$ & 0.6322 & 0.6322 \\
\hline 0.5 & 0 & 1.2307 & 1.2307 \\
\hline
\end{tabular}

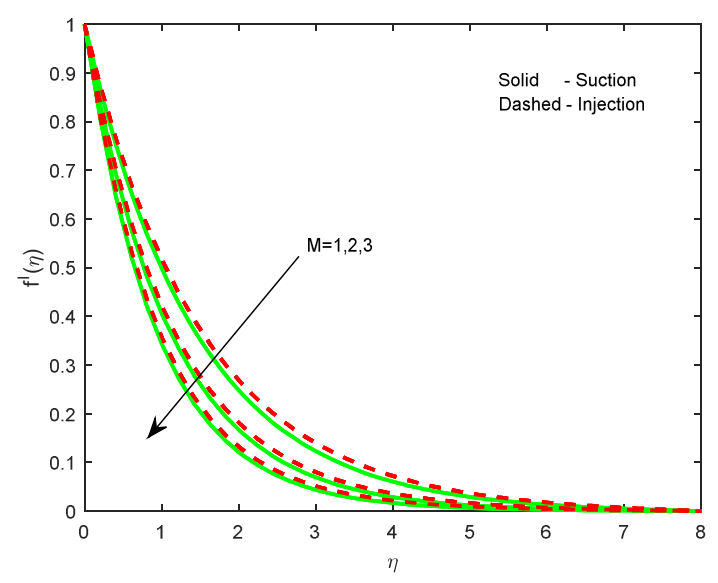

Fig. 2 Effect of $M$ on the velocity profile 


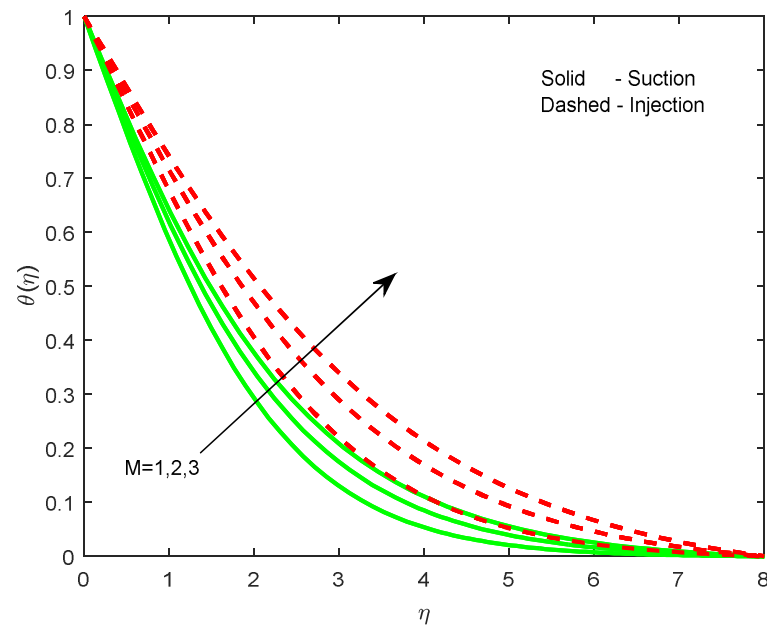

Fig. 3 Effect of $M$ on the temperature profile

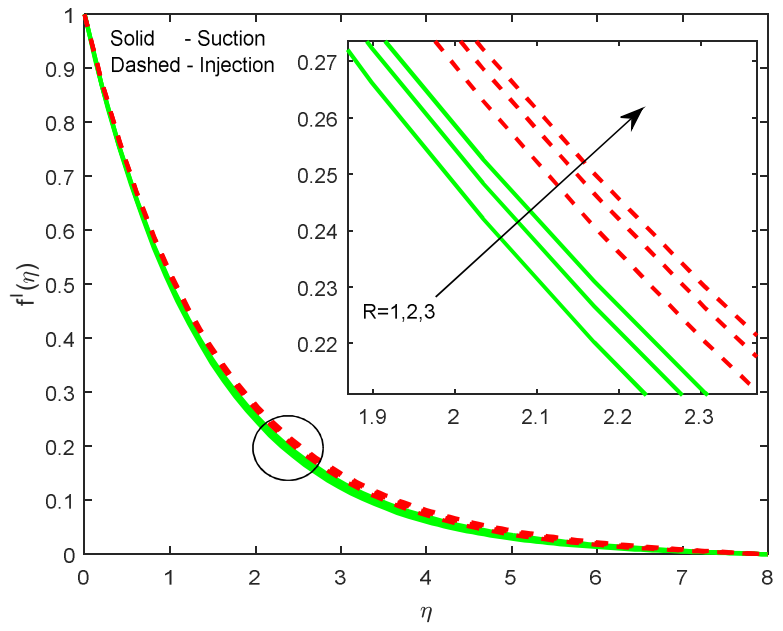

Fig. 4 Effect of $R$ on the velocity profile

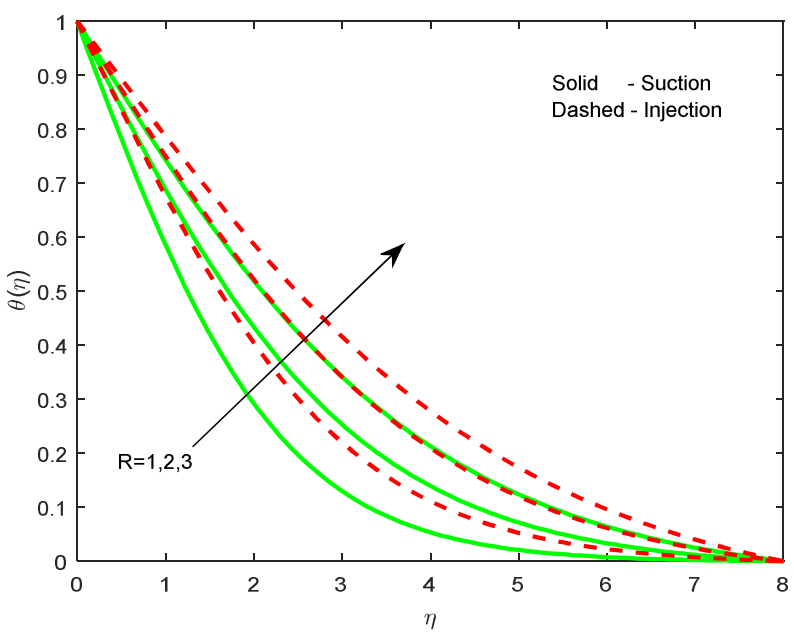

Fig. 5 Effect of $M$ on the temperature profiles

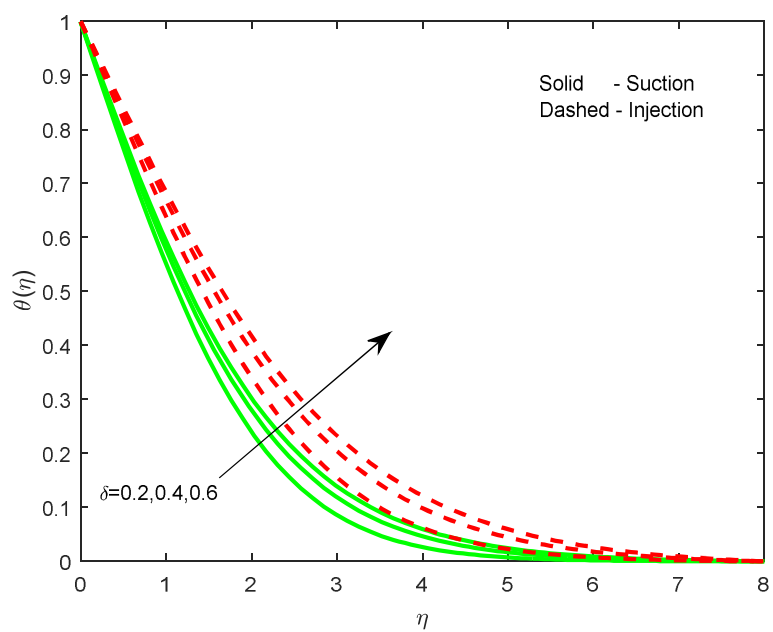

Fig. 6 Effect of $\delta$ on the temperature profile

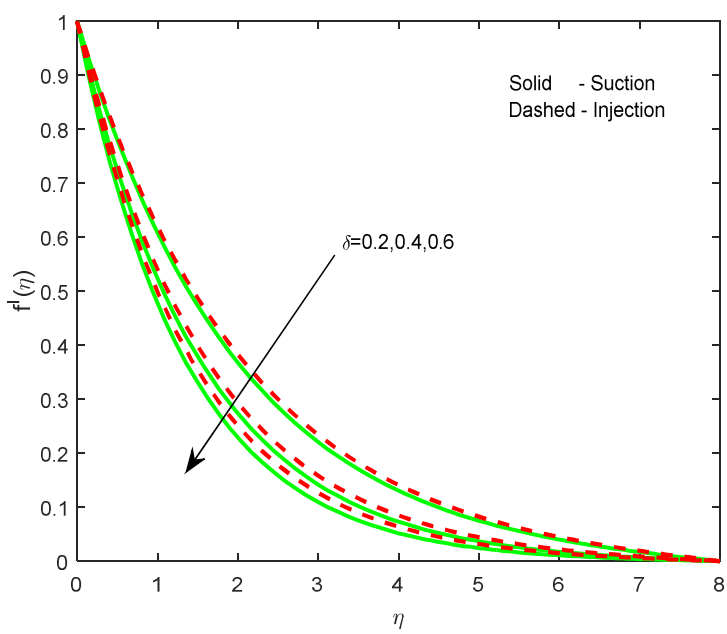

Fig. 7 Effect of $\delta$ on the velocity profile

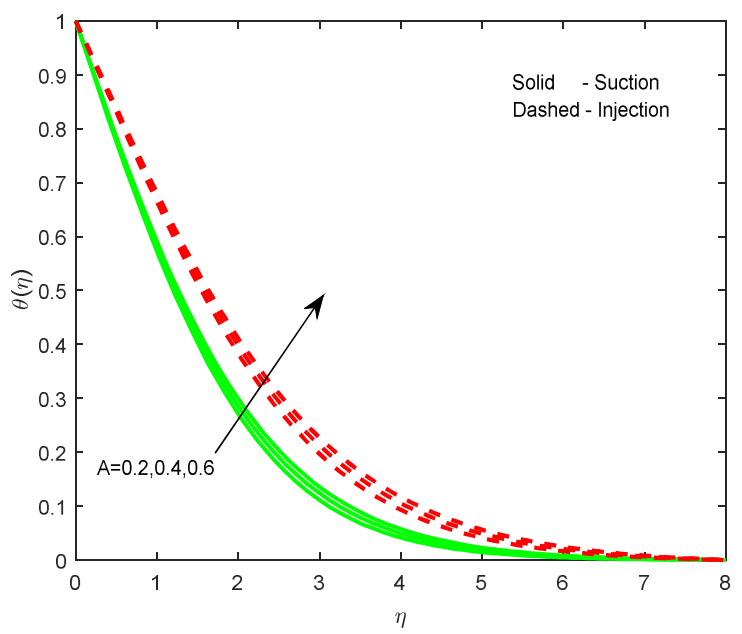

Fig. 8 Effect of $A$ on the temperature profile 


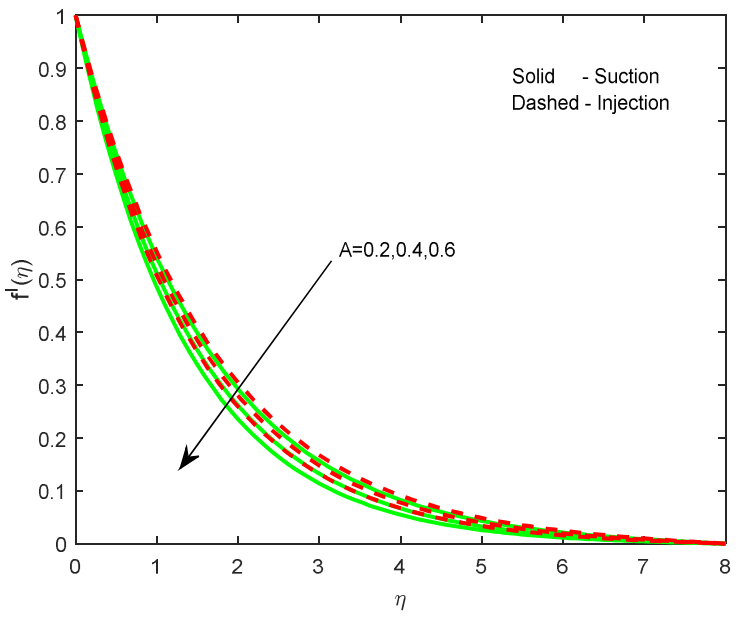

Fig. 9 Effect of $A$ on the velocity profile

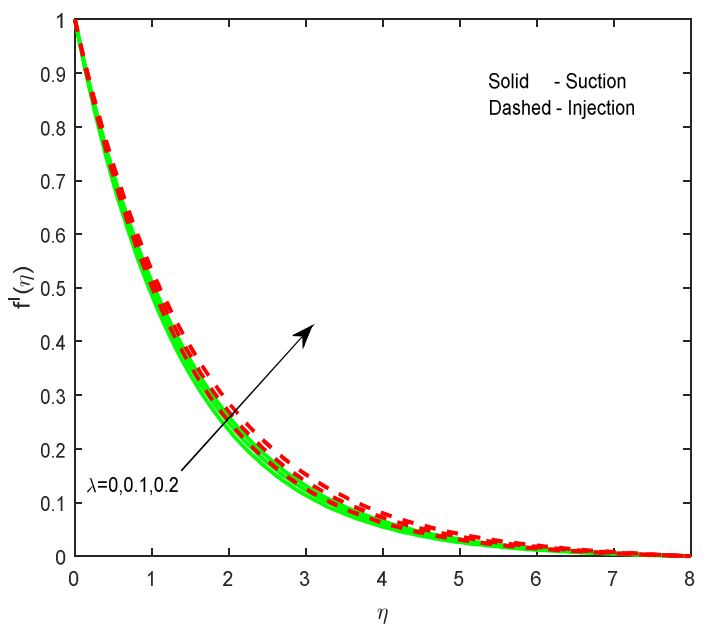

Fig. 10 Effect of $\lambda$ on the velocity profile

Table: 2. Physical parameter values in suction case

\begin{tabular}{|l|l|l|l|l|l|l|l|l|}
\hline$M$ & $R$ & $\delta$ & $A$ & $\lambda$ & $\theta_{w}$ & $\gamma$ & $f^{\prime \prime}(0)$ & $-\theta^{\prime}(0)$ \\
\hline 1 & & & & & & & -0.697581 & 0.441272 \\
\hline 2 & & & & & & & -0.905575 & 0.406931 \\
\hline 3 & & & & & & & -1.074704 & 0.382534 \\
\hline & 1 & & & & & & -0.697581 & 0.441272 \\
\hline & 2 & & & & & & -0.693222 & 0.320250 \\
\hline & 3 & & & & & & -0.690554 & 0.260523 \\
\hline & & .2 & & & & & -0.494778 & 0.479084 \\
\hline & & .4 & & & & & -0.646078 & 0.450472 \\
\hline & & .6 & & & & & -0.739755 & 0.433984 \\
\hline & & & .2 & & & & -0.612172 & 0.456688 \\
\hline & & & .4 & & & & -0.670031 & 0.446166 \\
\hline & & & .6 & & & & -0.724335 & 0.436596 \\
\hline & & & & 0 & & & -0.724026 & 0.436409 \\
\hline & & & & 0.1 & & & -0.697581 & 0.441272 \\
\hline & & & & 1.2 & & & -0.671576 & 0.445860 \\
\hline & & & & & 1 & & -0.698646 & 0.498675 \\
\hline & & & & & 1.1 & & -0.697581 & 0.441272 \\
\hline & & & & & 1.2 & & -0.696453 & 0.389190 \\
\hline & & & & & & 0 & -0.704278 & 0.832691 \\
\hline & & & & & & 0.5 & -0.702653 & 0.782062 \\
\hline & & & & & & 1 & -0.698646 & 0.498675 \\
\hline
\end{tabular}

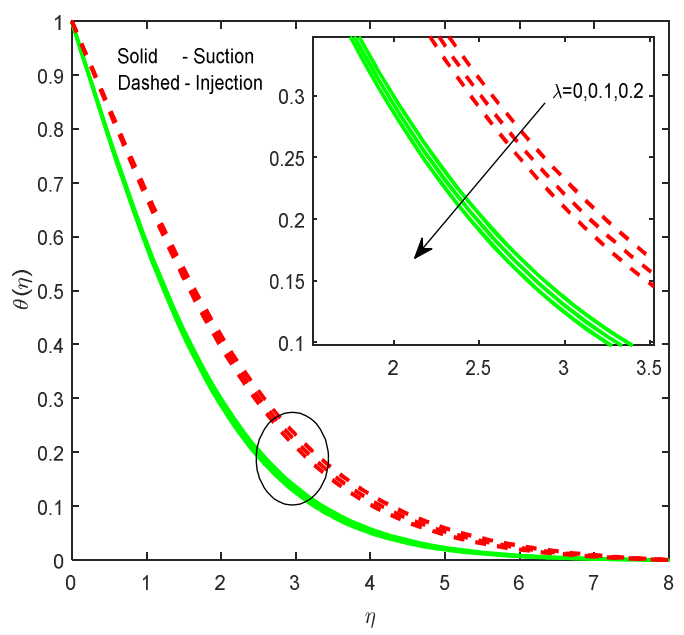

Fig. 11 Effect of $\lambda$ on the temperature profile

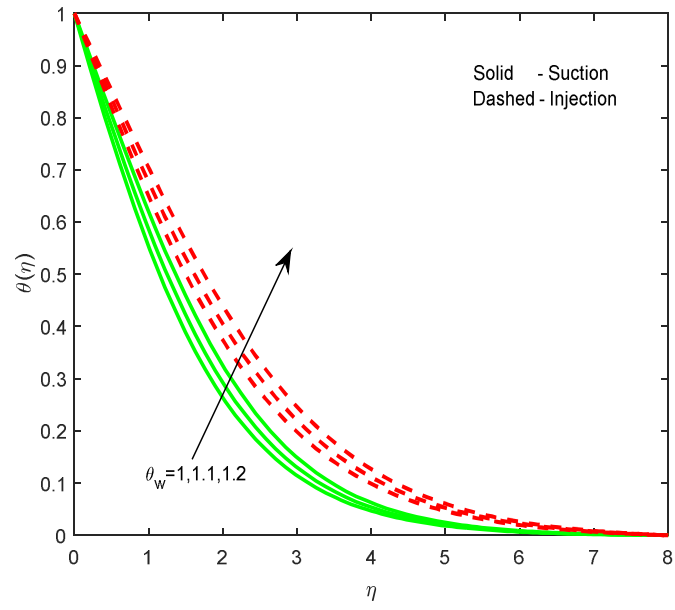

Fig. 12 Effect of $\theta_{w}$ on the temperature profile

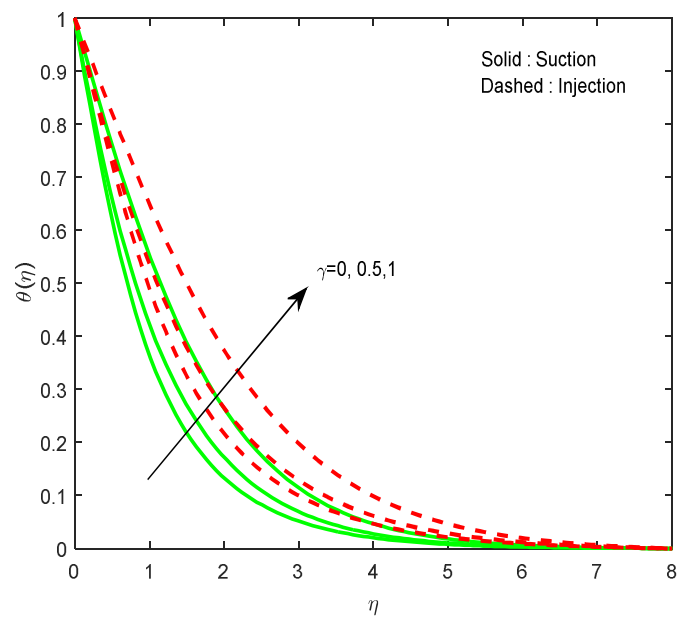

Fig. 13 Effect of $\gamma$ on the temperature profile 
Table: 3. Physical parameter in injection case

\begin{tabular}{|l|l|l|l|l|l|l|l|l|}
\hline$M$ & $R$ & $\delta$ & $A$ &.. & $\theta$ & $\gamma$ & $\mathrm{f}^{\prime \prime}(0)$ & $-\theta^{\prime}(0)$ \\
\hline 1 & & & & & & & -0.661544 & 0.320493 \\
\hline 2 & & & & & & & -0.870027 & 0.283029 \\
\hline 3 & & & & & & & -1.039548 & 0.257404 \\
\hline & 1 & & & & & & -0.661544 & 0.320493 \\
\hline & 2 & & & & & & -0.658168 & 0.246210 \\
\hline & 3 & & & & & & -0.656243 & 0.208905 \\
\hline & & .2 & & & & & -0.476284 & 0.358720 \\
\hline & & .4 & & & & & -0.614973 & 0.329622 \\
\hline & & .6 & & & & & -0.699447 & 0.313351 \\
\hline & & & .2 & & & & -0.595444 & 0.333662 \\
\hline & & & .4 & & & & -0.640440 & 0.324632 \\
\hline & & & .6 & & & & -0.681846 & 0.316573 \\
\hline & & & & 0 & & & -0.690695 & 0.313868 \\
\hline & & & & 0.1 & & & -0.661544 & 0.320493 \\
\hline & & & & 0.2 & & & -0.633074 & 0.326588 \\
\hline & & & & & 1 & & -0.662498 & 0.357302 \\
\hline & & & & & 1.1 & & -0.661544 & 0.320493 \\
\hline & & & & & 1.2 & & -0.660546 & 0.286453 \\
\hline & & & & & & 0 & -0.667548 & 0.546371 \\
\hline & & & & & & 0.5 & -0.666140 & 0.526867 \\
\hline & & & & & & 1 & -0.662498 & 0.357302 \\
\hline
\end{tabular}

\section{CONCLUSIONS}

Cattaneo-Christov heat flux effect on nonlinear radiative MHD flow of Casson fluid induced by a semi-infinite stretching surface is studied theoretically. Numerical results are presented for various parameters of interest and results are discussed with the help of graphs and tables.

The findings of the present study are as follows:

- Casson parameter helps to depreciate both skin friction coefficient and the heat transfer rate.

- $\quad$ Rise in buoyancy parameter improves the friction factor and heat transfer rate.

- $\quad$ An increase in temperature ratio parameter enhances the friction factor and depreciates the heat transfer rate.

- Thermal relaxation parameter have tendency to increase skin friction coefficient and reduces the heat transfer rate.

- Increasing the thermal radiation parameter enhances the friction factor and depreciates the heat transfer rate.

\section{NOMENCLATURE}

$u, v \quad$ velocity components along $x$ and $y$ direction $(\mathrm{m} / \mathrm{s})$

$g \quad$ acceleration due to gravity

$B_{0} \quad$ constant magnetic field $\left(\mathrm{A} \mathrm{m}^{-1}\right)$

$k$ thermal conductivity

a constant

$K^{*} \quad$ mean absorption coefficient

$C_{f x} \quad$ skin friction factor (Pascal)

$N u_{x} \quad$ Nusselt number

$T \quad$ temperature $(\mathrm{K})$

$T_{w} \quad$ temperature near the wall

$\mathrm{T}_{\infty} \quad$ temperature far away from the wall

$C \quad$ nanoparticle concentration (mole $\mathrm{m}^{-3}$ )
A viscosity ratio parameter

$\lambda$ buoyancy parameter

$M \quad$ magnetic field parameter

$\mathrm{Pr} \quad$ Prandtl number

$R \quad$ thermal radiation parameter

$\gamma \quad$ thermal relaxation parameter

$\theta_{w} \quad$ temperature ratio parameter

$S \quad$ suction/injection parameter

Greek Symbols

$\delta \quad$ Casson parameter

$\varepsilon \quad$ relaxation parameter for heat flux

$\rho \quad \operatorname{density}\left(\mathrm{kgm}^{-3}\right)$

$v \quad$ kinematic viscosity $\left(\mathrm{m}^{2} \mathrm{~s}^{-1}\right)$

$\rho c_{p} \quad$ specific heat capacity of the fluid

$\sigma \quad$ electric conductivity

$\mu \quad$ dynamic viscosity (kg/m.s)

$\beta \quad$ thermal expansion coefficient

$\sigma^{*} \quad$ Stefan-Boltzmann constant

$\theta \quad$ dimensionless temperature(K)

$\eta \quad$ dimensionless similarity variable

Superscripts

$w \quad$ condition on the sheet

$\infty \quad$ ambient temperature

\section{REFERENCES}

Abbasbandy, S., Hayat, T., Alsaedi, A. and Rashidi, M. M., 2014, "Numerical and Analytical Solutions for Falkner-Skan Flow of MHD Oldroyed-B Fluid," Int. J. Numer. Method Heat Fluid Flow, 24, 390-401. http://dx.doi.org/10.1108/HFF-05-2012-0096

Animasaun, I.L., Raju, C.S.K. and Sandeep,N., 2016, "Unequal Diffusivities Case of Homogeneous-Heterogeneous Reaction within Viscoelastic Fluid Flow in the Presence of Induced Magnetic Field and Nonlinear Thermal Radiation," Alex. Eng. J., 55, 1595-1606. http://dx.doi.org/10.1016/j.aej.2016.01.018

Cattaneo, C., 1948, "Sulla Conduzione del calore," Atti Semin. Mat Fis. Univ. Modena Reggio Emilia, 3, 83-101.

Christov, C.I., 2009, "On Frame Indifferent Formulation of the MaxwellCattaneo Model of Finite-speed Heat Conduction," Mechanics Research Communication, 36, 481-486.

http://dx.doi.org/10.1016/j.mechrescom.2008.11.003

Ciarletta, M., and Straughan, B., 2010, "Uniqueness and Structural Stability for the Cattaneo-Christov Equations," Mechanics Research Communications, 37, 445-447.

\section{http://dx.doi.org/10.1016/j.mechrescom.2010.06.002}

Elbashbeshy, E.M.A., 1998, "Heat Transfer over a Stretching Surface with Variable Surface Heat Flux," J. Phys. D: Appl. Phys. 31, 1951-1954. http://dx.doi.org/10.1016/j.camwa.2010.09.035

Fourier, J. B.J., 1822, “Theorie Analytique De La Chaleur,” Paris.

Gupta, P.S. and Gupta, A.S., 1977, "Heat and Mass Transfer on a Stretching Sheet with Suction or Blowing," Canda, J. Chem. Engng., 55, 744-746.

http://dx.doi.org/10.1002/cjce.5450550619 
Han, S., Zheng, L., Li, C. and Zhang, X., 2014, "Coupled Flow and Heat Transfer in Viscoelastic Fluid with Cattaneo-Christov Heat Flux Model," Appl. Math. Lett. , 38, 87-93.

http://dx.doi.org/10.1016/j.aml.2014.07.013

Hayat, T., Farooq, M., Alsaedi, A., and Falleh Al-Solamy, 2016, "Impact of Cattaneo-Christov Heat Flux in Flow Over a Stretching Sheet with Variable Thickness," AIP Advances, 8.

http://dx.doi.org/10.1063/1.4929523

Hayat, T., Ijaz Khan, M., Farooq, M., Tabassam Yasmeen and Alsaedi, A., 2016, "Stagnation Point Flow with Cattaneo-Christov Heat Flux and Homogeneous-Heterogeneous Reactions," Journal of Molecular Liquids, 220, 49-55.

http://dx.doi.org/10.1016/j.molliq.2016.04.032

Hayat, T., Imtiaz, M., Alsaedi, A. and Almezal, S., 2016, "On CattaneoChristov Heat Flux in MHD fFlow of Oldroyd-B Fluid with Homogeneous-Heterogeneous Reactions," J. Mag. Mag. Mat., 401, 296303.

http://dx.doi.org/10.1016/j.jmmm.2015.10.039

Jafar, K., Nazar, R., Ishak, A. and Pop, I., 2012, "MHD Flow and Heat Transfer over Stretching/Shrinking Sheets With External Magnetic Field, Viscous Dissipation and Joule Effects," Can. J. Chem. Eng., 90, 13361346.

http://dx.doi.org/10.1002/cjce.20609

Khan, J.A., Mustafa, M., Hayat, T. and Alsaedi, A., 2015, "Numerical Study of Cattaneo- Christov Heat Flux Model for Viscoelastic Flow Due To an Exponentially Stretching Surface," PLOS one, 10(9).

http://dx.doi.org/10.1371/journal.pone.0137363

McCormack, P.D. and Crane, L., 1973, Physical Fluid Dynamics, Academic Press, New York.

Mustafa, M., 2015, "Cattaneo-Christov Heat Flux Model for Rotating Floe and Heat Transfer of Upper-Convected Maxwell Fluid," AIP Adv., $5,047109$.

http://dx.doi.org/10.1063/1.4917306

Raju, C. S. K., Sandeep, N., Jayachandra Babu, M. and Sugunamma, V., 2016, "Dual Solution for Three-dimensional MHD Flow of a Nanofluid over a Nonlinearly Permeable Stretching Sheet," Alexandria Engineering Journal, 55, 151-162.

http://dx.doi.org/10.1016/j.aej.2015.12.017

Raju, C.S.K. and Sandeep, N., (2016), "Unsteady Three-Dimensional Flow of Casson-Carreau Fluids Past a Stretching Surface," Alexandria Eng. J., 55, 115-1126.

http://dx.doi.org/10.1016/j.aej.2016.03.023

Rashidi, M.M., Rostami, B., Freidoonimehr, N. and Abbasbandy, S., 2014, Free Convective Heat and Mass Transfer For MHD Fluid Flow over a Permeable Vertical Stretching Sheet in the Presence of Radiation and Buoyancy Effects," Aim Shams Engineering Journal, 5, 901-912. http://dx.doi.org/10.1016/j.asej.2014.02.007

Ramesh, G.K., Gireesha, B. J. and Bagewadi, C. S., 2012, "MHD Flow of a Dusty Fluid near the Stagnation Point over a Permeable Stretching
Sheet with Non-uniform Source/Sink," Int. J. of Heat and Mass Tran., 55, 4990-4907.

http://dx.doi.org/10.1016/j.ijheatmasstransfer.2012.05.003

Rashidi, M. M., Vishnu Ganesh, N., Abdul Hakeem, A.K. and Ganga, B., 2014, "Buoyancy Effect on MHD Flow of Nanofluid over a Stretching Sheet in the Presence of Thermal Radiation," J. of Molecular Liquids, 198, 234-238.

http://dx.doi.org/10.1016/j.molliq.2014.06.037

Sandeep, N., Sulochana, C. and Sugunamma, V., 2015, "Radiation and Magnetic Field Effects on Unsteady Mixed Convection Flow over a Vertical Stretching/shrinking Surface with Suction/injection," Industrial Eng. Letters, 5(1), 127-136.

www.iiste.org/Journals/index.php/IEL/article/viewFile/22278/22784

Sathish Kumar, M., Sandeep, N. and Rushi Kumar, B., 2016, "Dual Solution Form Heat and Mass Transfer in MHD Bio-convective Flow Over A Stretching/shrinking Surface with Suction/injection," Int. J. of Eng. Research in Africa, 21, 84-101.

http://dx.doi.org/10.4028/www.scientific.net/JERA.21.84

Sandeep, N. and Sulochana, C., 2016, "Dual Solution of Radiative MHD Nanofluid Flow over Exponentially Stretching Sheet with Heat Generation/absorption," Appl Nanosci., 6, 131-139.

http:dx.doi.org/10.1007/s13204-015-0420-z

Sandeep, N., Koriko, O.K. and Animasaun, I.L., 2016, "Modified Kinematic Viscosity Model For 3d-casson Fluid Flow within Boundary Layer Formed on a Surface at Absolute Zero,” J. of Mole. Liquids, 221, 1197-1206.

http://dx.doi.org/10.1016/j.molliq.2016.06.049

Straughan, B., 2010, "Thermal Convection with the Cattaneo-Christov Model," Int. J. of Heat and Mass Tran., 53, 95-98.

http://dx.doi.org/10.1016/j.ijheatmasstransfer.2009.10.001

Subhas Abel, M., and Mahesha, N., 2008, "Heat Transfer in MHD Viscoelastic Fluid Flow over A Stretching Sheet with Variable Thermal Conductivity, Non-uniform Heat Source and Radiation," Applied Mathematical Modelling, 32, 1965-1983.

http://dx.doi.org/10.1016/j.apm.2007.06.038

Sulochana, C., Ashwin Kumar, G.P. and Sandeep, N., 2016, "Similarity Solution of 3D Casson Nonofluid Flow over a Stretching Sheet with Convective Boundary Conditions," J. of the Nig. Math. Soc., 35, 128141.

http://dx.doi.org/10.1016/j.jnnms.2016.01.001

Tibullo, V. and Zampoli, V., 2011, "A Uniqueness Result for the Cattaneo-Christov Heat Conduction Model Applied to Incompressible Fluids," Mech. Res. Commun. , 38, 77-99.

http://dx.doi.org/10.1016/j.mechrescom.2010.10.008

Vajravelu, K., 2001, "Viscous Flow over a Nonlinearly Stretching Sheet," J. Appl. Math. And Comput., 124 (3), 282-288. http://dx.doi.org/10.1016/S0096-3003(00)00062-X

Vajravelu, K., Prasad, K.V. and Hanumesh Vaidya, 2016, "Influence of Hall Current on MHD Flow and Heat Transfer over a Slender Stretching 
Sheet in the Presence of Variable Fluid Properties," Comm. in Num.Anal., 2016 (1), 17-36.

http://dx.doi.org/10.5899/2016/cna-00251

Sandeep, N., 2016, "Effect of Aligned Magnetic Field on Liquid Thin Film Flow of Magnetic-Nanofluid Embedded with Graphene Nanoparticles," Advanced Powder Technology, (in Press).

http://dx.doi.org/10.1016/j.apt.2016.12.012
Ramana Reddy, J.V. , Sugunamma, V. , Sandeep, N. , 2017, “Effect of Frictional Heating on Radiative Ferrofluid Flow over a Slandering Stretching Sheet with Aligned Magnetic Field," Europen Physical Journal Plus, 132:7

http://doi:10.1140/epjp/i2017-11287-1

Ali, M.E., Sandeep, N., 2017, "Cattaneo-Christov Model for Radiative Heat Transfer of Magnetohydrodynamic Casson-Ferrofluid: A Numerical Study," Results in Physics, 7, 21-30.

http://dx.doi.org/10.1016/j.rinp.2016.11.055 